\title{
EFFECT OF 4-ACYL-ISOCOUMARINS ON IgE-MEDIATED AND MANNAN-INDUCED HISTAMINE RELEASE FROM ISOLATED RAT MAST CELLS
}

\author{
Isami WAKI, Yoji DEGUCHI and Masayasu KIMURA \\ Department of Chemical Pharmacology. Faculty of Pharmaceutical Sciences, \\ Toyama Medical and Pharmaceutical University, 2630 Sugitani, Toyama 930-01. Japan
}

Accepted April 5, 1981

\begin{abstract}
The 4-acyl-isocoumarins which inhibit compound 48/80-induced histamine release were studied to determine whether or not they could inhibit lgE-mediated and mannan-induced histamine release from isolated rat peritoneal mast cells. The lgE-mediated release was induced mainly in the isolated rat peritoneal cells sensitized in vitro with mouse IgE, and released histamine was assayed by fluorometry. Oosponol (4-hydroxyacetyl-8-hydroxyisocoumarin) and 8-deoxy-oosponol glycinate showed inhibition of both the IgE-mediated and the mannan-induced histamine release, in the same dose range $(2-8 \mu \mathrm{M}$ and 4-16 $\mu \mathrm{M}$, respectively). KIT-302 (4-(4'-carboxy-benzoyl)-isocoumarin) and its analogues showed potentiation (to approx. 2 -fold) of both the $\mathrm{IgE}$-mediated and the mannaninduced release at lower doses $(2-30 \mu \mathrm{M}$ for KIT-302) and inhibition at higher doses. KIT-302 at the lower doses showed potentiation of ATP-induced histamine release and also of the second stage of the $\mathrm{lgE}$ mediated release. Inhibitory effect of KIT-302 on the 48/80-induced histamine release was also observed in $\mathrm{Ca}^{++}$-free medium.
\end{abstract}

Oosponol (4-hydroxyacetyl-8-hydroxyisocoumarin) and some structurally related compounds were found to inhibit compound 48/80-induced histamine release from isolated rat mast cells (1). Molecular orbital studies on the inhibitory effect of the isocoumarins showed that the stronger was the total positive charge of the benzene ring, or the total negative one of the lactone ring, the greater was the inhibitory activity of isocoumarin (2). Compound 48/80, a basic histamine releaser, is capable of exerting its action on isolated mast cells in $\mathrm{Ca}^{++}$nonadded medium (3). On the other hand. antigen-induced $\mathrm{lgE}$-mediated histamine release from isolated mast cells is marked when tested in the medium containing both
$\mathrm{Ca}^{++}$and phosphatidyl-L-serine (PS) (4-6). Mannan-induced histamine release is similar to $\lg$ E-mediated release (7). Therefore. we attempted to determine whether the isocoumarin compounds could inhibit the IgEmediated and the mannan-induced histamine release and whether the effectiveness of the compounds depended on the type of histamine release from isolated rat mast cells.

\section{MATERIALS AND METHODS}

Peritoneal mast cells: Male SpragueDawley rats weighing $300-400 \mathrm{~g}$ were sacrificed to obtain peritoneal cells and the isolated cells without further purification were suspended in Tris-buffered salt solution. $\mathrm{pH}$ 7.4, as described previously (7). 
Release of histamine: Peritoneal cell suspensions $(0.2 \mathrm{ml})$ were pretreated with or without a solution $(0.2 \mathrm{ml})$ of isocoumarin to be tested and then incubated with one of histamine releasers $(0.2 \mathrm{ml})$ at $25^{\circ} \mathrm{C}$ with shaking at $120 \mathrm{~Hz}$. If necessary. PS was added at the final concentration of $10 \mathrm{\mu g} /$ $\mathrm{ml}$. Histamine was assayed by fluorometry and percentage of the released histamine to the total histamine content was calculated as described previously (7).

Sensitization: Isolated rat peritoneal cells were incubated at $37^{\circ} \mathrm{C}$ with mouse anti-egg albumin (EA) sera in an atmosphere of $95 \%$ $\mathrm{O}_{2}: 5 \% \mathrm{CO}_{2}$ with shaking at $60 \mathrm{~Hz}$. One hour later, the cells were washed with the cold medium and used as $\mathrm{lgE}$-sensitized cells. The anti-sera were obtained from $\mathrm{C} 57 \mathrm{BL} / 6$ mice hyperimmunized with $10 \mu \mathrm{g}$ EA included in $1 \mathrm{mg}$ aluminum hydroxide gel, according to the method of Koenig et al. (8). The titer of the sera, the highest dilution inducing passive cutaneous anaphylaxis in rats at a $2-\mathrm{hr}$ latent period, was $1: 800$. The $1 / 50$ dilution was chosen for the sensitization. During the sensitization periods, the normal bovine serum inactivated by heating at $56^{\circ} \mathrm{C}$ for $30 \mathrm{~min}$ and glucose were added to the medium at the final concentrations of $10 \%$ and $1 \mathrm{mg} / \mathrm{ml}$, respectively, to minimize the decrease in the histamine content of mast cells. Rats were also sensitized actively with EA as described previously (7).

Fractionation of peritoneal cells: Peritoneal cells were fractionated on glass wool (Jintan Terumo, Ltd., Tokyo) columns (9). The cells were incubated with the glass wool at $37^{\circ} \mathrm{C}$ for $1 \mathrm{hr}$ and then eluted with the medium at $37^{\circ} \mathrm{C}$. The eluted cells were expressed as glass wool-passed celis. Cells fixed to the glass wool were then eluted with the ice-cold medium with shaking and expressed as fixed cells. Purification of mast cells was also performed using gum arabic as described previously (1).
Compounds: Following isocoumarin (IC) compounds were synthetized in our own laboratory: DOG (4- $\left.\mathrm{COCH}_{2} \mathrm{OCOCH}_{2} \mathrm{NH}_{2} I \mathrm{C}\right)$, $\mathrm{KIT}-302 \quad\left(4-\mathrm{CO}-\mathrm{C}_{6} \mathrm{H}_{4}-4^{\prime}-\mathrm{COOH}\right.$ IC triethanolamine salt), $\mathrm{KIT}-302 \mathrm{H}\left(4-\mathrm{CO}-\mathrm{C}_{6} \mathrm{H}_{4}\right.$ $4^{\prime}-\mathrm{COOH}$ IC), KIT-306 (4-CO- $\mathrm{C}_{6} \mathrm{H}_{4}-4^{\prime}-$ $\left.\mathrm{COOC}_{5} \mathrm{H}_{11} \mathrm{IC}\right)$, KIT-2O1 (4- $\mathrm{C}_{6} \mathrm{H}_{4}-\mathrm{OH} \mathrm{IC)}$. Oosponol and disodium cromoglycate (DSCG) were the gift of the late Prof. S. Ohashi (Nippon Medical School, Tokyo) and Fujisawa Pharmaceutical Co., Ltd. (Osaka), respectively. Other compounds were obtained from Nakarai Chemicals, Ltd. (Kyoto).

\section{RESULTS}

Effect on IgE-mediated histamine release: The relation of the time of pretreatment with a 4-acylisocoumarin compound to the effect on $\mathrm{IgE}$-mediated histamine release was investigated using the rat mast cells sensitized in vitro with mouse anti-EA sera. Figure 1-a shows that DOG had an inhibitory effect on the histamine release in the 30-sec pretreatment. The effect increased with increase in the pretreatment time. On the other hand. KIT-302 showed enhancement followed by inhibition of the histamine release. The effect of DOG and KIT-302 was also observed $2 \mathrm{hr}$ or longer after the cells were washed with the normal medium. The inhibitory effect of KIT-302 was not overcome by increasing the dose of the antigen (Fig. 1-b).

Dose-response relations for the isocoumarins and DSCG are summarized in Fig. 2. DOG inhibited the release in a dosedependent fashion, whereas KIT-302 potentiated the release at lower doses and inhibited at higher doses. With regard to the histamine release from actively sensitized rat mast cells. KIT-302H (free acid of KIT-302) had a similar effect (Fig. 2).

Effect on mannan-induced histamine release: The effect of isocoumarin compounds on mannan-induced histamine release was 

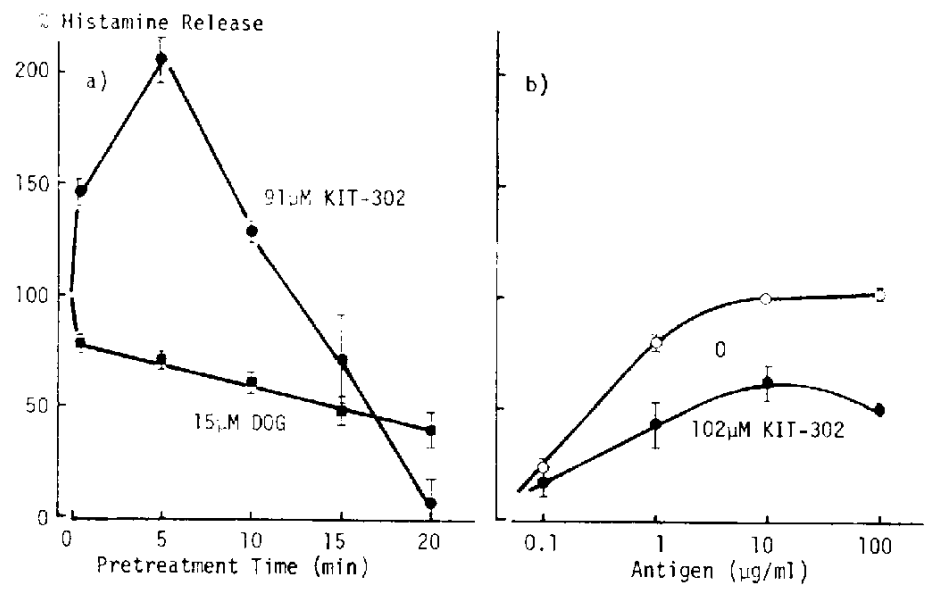

Fig. 1. Effect of 4-acyl-Isocoumarins on IgE-mediated histamine release from isolated rat peritoneal mast cells. Histamine release was expressed as $\%$ of the control histamine release induced by $10 \% \mathrm{~g} / \mathrm{ml}$ of egg albumin (EA) in the absence of 4 -acyl-isocoumarin. a): Effect of pretreatment time. The control histamine release induced by $10 \mu \mathrm{g} / \mathrm{ml} \mathrm{EA}$ was $35 \pm 4.3 \%$ of the total (mean \pm S.E., $n=4$ ). Each point is the mean of 4 experiments. Vertical bars represent the S.E. b): Dose-response curves for lgE-mediated histamine release with or without 10 -min pretreatment with KIT-302. The control histamine release was $34 \pm 3.5 \%$ of the total $(n=6)$. Each point is the mean of $4-6$ experiments. Vertical bars represent the S.E.

investigated and compared with that of the IgE-mediated release. Figure 3 shows that KIT-302 potentiated and inhibited the mannan-induced release in a manner similar to that seen in the case of $\mathrm{IgE}$-mediated release. When the cells were pretreated for $1 \mathrm{hr}$ with $17 \mu \mathrm{M} \mathrm{KIT-302,} \mathrm{the} \mathrm{release} \mathrm{was}$ approx. 140\%. At higher doses of KIT-302. the potentiation was apparently nil.

Dose-response curves for the isocoumarins are shown in Fig. 4 together with that for DSCG. Oosponol and DOG had an inhibitory effect, whereas KIT-302 and KIT-306 had both potentiating and inhibiting effects. Such biphasic effects were also observed in the case of KIT-201 (data not shown).

When the time of pretreatment with DSCG was increased to $15 \mathrm{~min}$. DSCG potentiated the mannan-induced as well as the $\operatorname{lgE}$ mediated histamine release. The increment of histamine release was $10-20 \%$ at doses of 0.1-1 $/ \mathrm{M}$. On the other hand, oosponol and DOG never potentiated the histamine release.

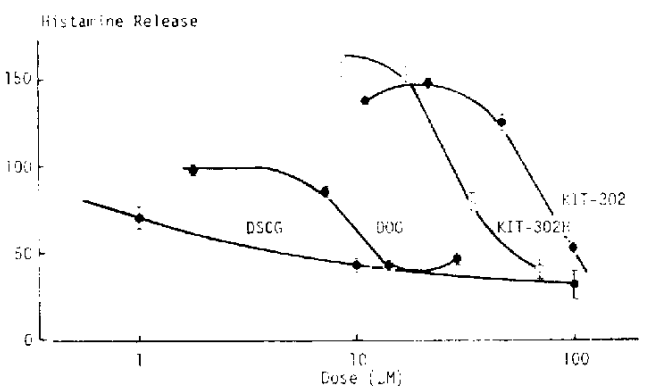

Fig. 2. Dose-response curves for actions of disodium cromoglycate (DSCG, 10-sec pretreatment) and 4-acyl-isocoumarins (15-min pretreatment) on lgE-mediated histamine release. Resporise was expressed as \% of the control histamine release induced by $10 \mu \mathrm{g} / \mathrm{ml}$ EA. In the passively sensitized cells control histamine release was $30 \pm 6.9 \%$ of the total ( $n=9)$, whereas the control histamine release in the actively sensitized cells (O) was $24 \pm 1.2 \%(n=6)$. The histamine release in the presence of $0.1 \mu \mathrm{M}$ DSCG was $105 \pm 1.2 \%$ $(n=6)$. Each point is the mean of $3-6$ experiments. Vertical bars represent the S.E. 

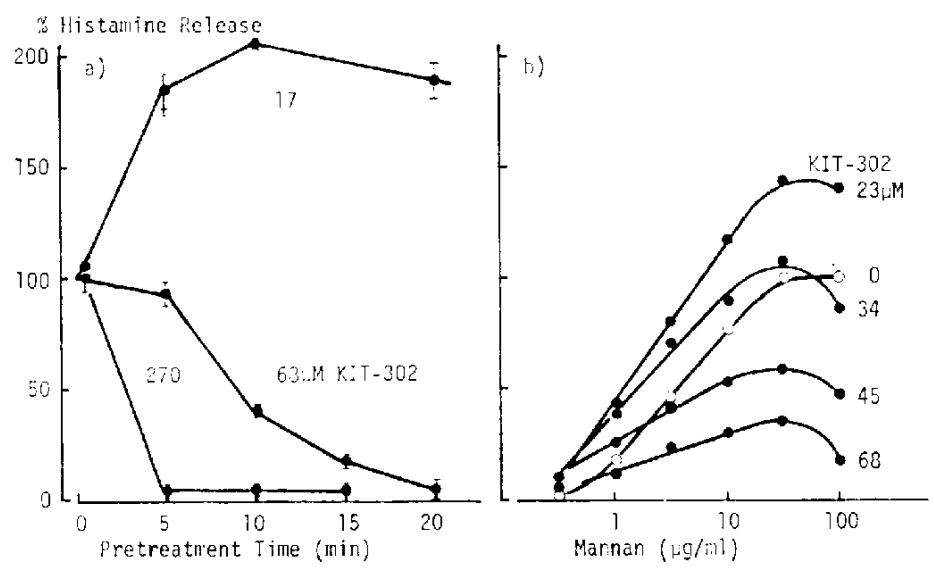

Fig. 3. Effect of KIT-302 on mannan-induced histamine release from isolated rat peritoneal mast cells. Histamine release was expressed as \% of the control histamine release induced by $30 \mu \mathrm{g} / \mathrm{ml}$ mannan in the absence of KIT-302. a): Effect of pretreatment time. The control histamine release inducod by $30 \% \mathrm{~g} / \mathrm{ml}$ mannan was $14 \pm 1.9 \%$ of the total $(n=6)$. Each point is the mean of 3-6 experiments. Vertical bars represent the S.E. b): Dose-response curves for mannan-induced histamine release with (O) or without (O) 15-min pretreatment with various doses of KIT-302. The control histamine release was $36 \pm 2.4 \%$ of the total $(n=10)$. Each point is the mean of duplicate experiments.

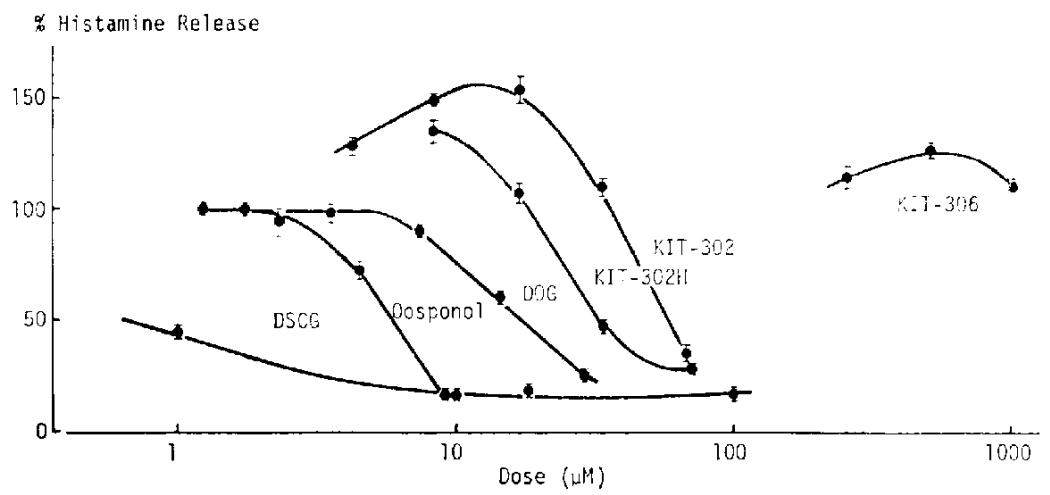

Fig. 4. Dose-response curves for actions of DSCG (10-sec pretreatment) and 4-acylisocoumarins (15-min pretreatment) on mannan-induced histamine release. Response was expressed as \% of the control histamine release induced by $30 \% \mathrm{~g} / \mathrm{ml}$ mannan, which was $40 \pm 1.7 \%$ of the total $(n=15)$. The histamine reloase in the presence of $0.1 \mu \mathrm{M}$ DSCG was $72 \pm 0.6 \%(n=3)$. Each point is the mean of $3-6$ experiments. Vertical bars represent the S.E.

In different cell fractions obtained from the same pool of peritoneal cells, the potentiating effect of KIT-302 was observed. in the same dose range (Fig. 5). Even in highly purified mast cells (approx. 95\%). the effect was apparent, despite the gum arabic-induced desensitization to mannan.

Influence of KIT-302 on rate of cell desensitization: The effect of KIT-302 on the rate of cell desensitization to mannan was examined using a method similar to that of Baxter et al. (10), and the results are 
summarized in Table 1. Each index of residual sensitivity to mannan $\|$ in the presence of KIT-302 was not higher than the corresponding control value in the absence of KIT-302. KIT-302 tested at $37^{\circ} \mathrm{C}$ potentiated the mannan-induced release to the same extent seen at $25^{\circ} \mathrm{C}$.

Influence of KIT-302 on effect of extracellular $\mathrm{Ca}^{++}$: ATP-induced histamine release from mast cells suspended in the

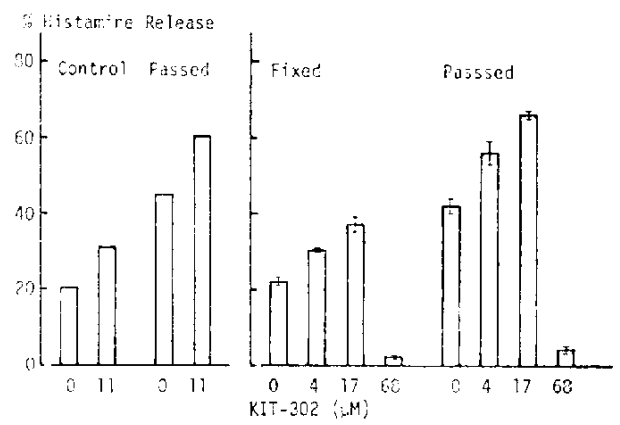

Fig. 5. Effect of KIT-302 on mannan-induced histamine release from different peritoneal cells. Control : crude peritoneal cells containing approx. 6\% mast cells. Passed : celis passed through glass fiber column at $37^{\circ} \mathrm{C}$, containing approx. $30 \%$ mast cells. Fixed : cells fixed to glass fiber at $37^{\circ} \mathrm{C}$ followed by elution with cold medium and shaking, containing approx. $4 \%$ mast cells. The histamine release induced by $30 \mu \mathrm{g} / \mathrm{ml}$ mannan was expressed as $\%$ of the total. Each column with a vertical bar represents the mean release of 3 experiments. Vertical bars represent the S.E. Each column without a vertical bar represents the mean of duplicate experiments. medium not containing PS is no less marked than that in the medium containing PS (11). That ATP-induced release in the absence of PS was enhanced by a lower dose of KIT-302 (Fig. 6).

When KIT-302 (11 $\mu \mathrm{M})$ was added to the second stage of the lgE-mediated histamine release (12), it potentiated the release (310\% of the control release). The influence on the first stage was not determined because of persistence of the KIT-302 effect. In the presence of KIT-302 during both the stages, the histamine release was $350 \%$ of the control value.

The relationship of the inhibitory effect of KIT-302 to the effect of extracellular

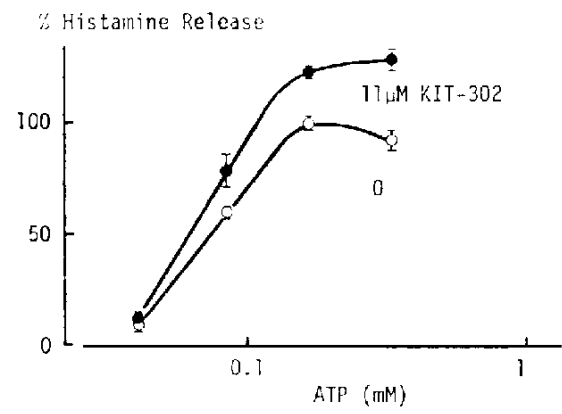

Fig. 6. Dose-response curves for ATP-induced histamine release with $(\mathbf{O})$ or without (O) 15-min pretreatment with $11 \mu \mathrm{M}$ KIT-302. Histamine release was expressed as \% of the control histamine release induced by $165 \mu \mathrm{M}$ ATP, which amounted to $38 \pm 4.4 \%$ of the total $(n=6)$. Each point is the mean of 3-6 experiments. Vertical bars represent the S.E.

Table 1. Effect of KIT-302 on the rate of coll desensitization to mannan

\begin{tabular}{|c|c|c|c|c|c|}
\hline $\begin{array}{r}\mathrm{KIT}-302 \\
\mu \mathrm{M}\end{array}$ & $\begin{array}{c}\text { Mannan } \\
\mu \mathrm{g} / \mathrm{ml} \\
\mathrm{II}\end{array}$ & $\begin{array}{c}\text { \%release } \\
\text { by } \\
I(a)\end{array}$ & $\begin{array}{c}\text { \%release } \\
\text { by } \\
(1+11)(b)\end{array}$ & $\begin{array}{c}\text { \%release } \\
\text { by } \\
1+11^{*} \text { (c) }\end{array}$ & $\begin{array}{l}c-a^{* *} \\
b-a\end{array}$ \\
\hline 0 & 0.330 & $6 \pm 1.5$ & $47 \pm 4.9$ & $40 \pm 6.3$ & $0.82 \pm 0.05$ \\
\hline 11 & 0.330 & $11 \pm 0.3$ & $64 \pm 5.1$ & $53 \pm 6.9$ & $0.77 \pm 0.06$ \\
\hline 0 & 330 & $15 \pm 2.9$ & $32 \pm 2.3$ & $20 \pm 3.6$ & $0.27 \pm 0.05$ \\
\hline 11 & 330 & $35 \pm 0.8$ & $53 \pm 0.5$ & $37 \pm 2.0$ & $0.13 \pm 0.06$ \\
\hline
\end{tabular}

Each value represents the mean \pm S.E. of 3 experiments. "Mannan II was added 5 min after the addition of mannan I. **An index of residual sensitivity to mannan 11 added 5 min after the challenge with mannan 1. 


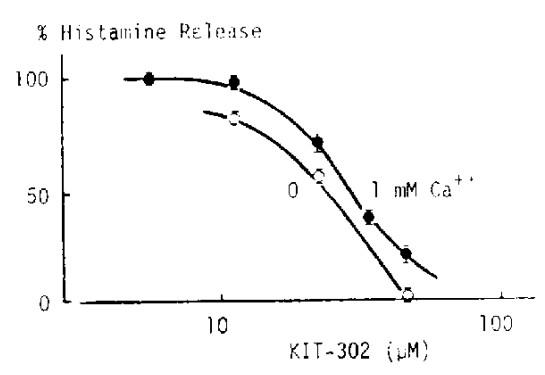

Fig. 7. Dose-response relationship for action of KIT-302 on compound 48/80-induced histamine release from isolated rat peritoneal mast cells in $\mathrm{Ca}^{++}$-free (O) and the normal (O) medium. Response was expressed as $\%$ of the control histamine release induced by $0.3 \mu \mathrm{g} / \mathrm{m}$ of compound $48 / 80$. which was $58 \pm 0.9 \%$ of the total $(n=6)$ in the $\mathrm{Ca}^{+-}$-free and $50 \pm 2.4 \%$ $(n=6)$ in the normal medium. Each point is the mean of 4-6 experiments. Vertical bars represent the S.E.

$\mathrm{Ca}^{++}$was then determined. For this purpose, compound 48/80-induced histamine release from peritoneal cells suspended in $\mathrm{Ca}^{++}$-free medium containing $1 \mathrm{mM}$ ethylene glycol bis-( $\beta$-aminoethyl ether)-N,N,N',N'-tetraacetic acid was used as a test system. The inhibitory effect of KIT-302 on the release in the absence of extracellular $\mathrm{Ca}^{++}$was no less marked than that on the release in the normal medium (Fig. 7).

\section{DISCUSSION}

The isocoumarin derivatives, which inhibit compound 48/80-induced histamine release (1). were studied to determine whether or not they could inhibit different types of histamine release from isolated rat mast cells, IgE-mediated histamine release was induced mainly in the rat peritoneal mast cells passively sensitized in vitro with mouse antisera containing lgE directed against EA. Such was an application of the results of Koenig et al. (8). who had reported that antigen-induced histamine release from rat cells sensitized with mouse antisera was IgE-mediated release from rat mast cells. This method was far more productive than that using cells sensitized with rat antisera, since in the latter, appropriate serum has to use for an adequate sensitization of peritoneal cells in vitro, on an empirical basis (13). Under our experimental conditions, IgEmediated release was increased by increasing the dose of antigen and/or antisera, and DSCG (10-sec pretreatment) showed inhibition of the release in the same dose range with which it inhibited the antigen-induced histamine release from actively sensitized rat peritoneal cells (14). The results of the effect of test compounds on the IgEmediated histamine release were consistent with those of the effect on mannan-induced histamine release, showing that the mannaninduced histamine release can serve as a simple, economical assay system for potential inhibitors of $\mathrm{lg} \mathrm{E}$-mediated histamine release.

Isocoumarin derivatives can be classified into two groups. The first group contains oosponol and DOG and can inhibit $\lg E$ mediated, mannan-induced and compound $48 / 80$-induced histamine release. This group of isocoumarins inhibited all the types of histamine release tested and the inhibitory action of these compounds was observed in $\mathrm{Ca}^{++}$-free medium. The second group contains KIT-302, KIT-306 and other compounds, and such potentiated the effects at lower doses on the $\lg E$-mediated, the mannan-induced and the ATP-induced release but not on the compound 48/80induced release. At higher doses, the compounds tested inhibited the release. The potentiation induced by isocoumarins does not seem to be mediated by the inhibition of the rate of cell desensitization to releasers or of PS action. but probably is mediated by the increased translocation of extracellular $\mathrm{Ca}^{++}$into the mast cells. When KIT-302 was applied to the second stage of the $\mathrm{IgE}$ mediated release, the potentiation was still observed, thus supporting our proposal.

In view of structure-activity relationships, 
the compound may have a potentiating effect when the substituents in the 4-position of isocoumarin contain a benzene ring. On the other hand, the isocoumarin compounds containing an aliphatic acyl group at the 4-position may have only inhibitory effects.

It is concluded that the effects of isocoumarin derivatives on histamine release from isolated rat mast cells are inhibition and/or potentiation and that these effects may be mediated by independent mechanisms.

\section{REFERENCES}

1) Kimura, M., Waki, I. and Kokubo, M.: Inhibition of compound 48/80-induced histamine release from isolated rat mast cells by oosponol-related compounds (4-acyl-isocoumarins). Japan. J. Pharmacol. 28, 693-697 (1978)

2) Nagahara, S., Deguchi, Y., Kimura, M. and Waki, l.: Molecular orbital study on isocoumarin compound. Approach to their activity of histamine release inhibition. Contribution from the Research Group on Atoms and Molecules 15. 104-110 (1979)

3) Saeki, K.: Effects of compound $48 / 80$, chymotrypsin and antiserum on isolated mast cells under aerobic and anacrobic conditions. Japan. J. Pharmacol. 14, 375-390 (1964)

4) Goth, A., Adams, H.R. and Knoohuizen, M.: Phosphatidylserine: selective enhancer of histamine release. Science 173, 1034-1035 (1971)

5) Mongar, J.L. and Svec, P.: The effect of phospholipids on anaphylactic histamine release. Brit. J. Pharmacol. 46, 741-752 (1972)

6) Foreman, J.C. and Mongar, J.L.: The role of the alkaline earth ions in anaphylactic histamine secretion. J. Physiol. 224, 753-769 (1972)

7) Waki, 1. and Kimura, M.: Possible role of IgEconstituent carbohydrate in the mediation of histamine release. Japan. J. Pharmacol. 28, 739-745 (1978)

8) Koenig, W., Okudaira, H. and Ishizaka, K.: Specific binding of mouse $\mathrm{IgE}$ with rat mast cells. J. Immunol. 112, 1652-1659 (1974)

9) Gesner, B.M. and Howard, J.G.: The isolation of lymphocytes and marcrophages. Handbook of Experimental Immunology. Edited by Weir, D.M., p. 1009-1033, Blackwell Scientific Publications, Oxford and Edinburgh (1967)

10) Baxter, J.H. and Adamik, R.: Effects of various conditions on rate of release and rate of cell desensitization. J. Immunol. 114, 1034-1041 (1975)

11) Krueger, P.G., Bloom, G.D. and Diamant, B.: Structural aspects of histamine release in rat peritoneal mast cells-.-Effects of adenosine 5 -triphosphate and role of calcium. Int. Archs Allergy appl. Immunol. 47, 1-13 (1974)

12) Lichtenstein, L.M. and DeBernardo, R.: The immediate allergic response: in vitro action of crclic AMP-active and other drugs on the two stages of histamine release. J. Immunol. 107. 1131-1136 (1971)

13) Evans, D.P. and Thomson, D.S.: Histamine release from rat mast cells passively sensitised with homocytotropic (IgE) antibody. Int. Archs Allergy appl. Immunol. 43, 217-231 (1972)

14) Garland, L.G. and Mongar, J.L.: Inhibition by cromoglycate of histamine release from rat peritoneal mast cells induced by mixtures of dextran, phosphatidyl serin and calcium ions. Brit. J. Pharmacol. 50, 137-143 (1974) 